\title{
Can MDCT Measures of Upper Airway Dimensions and Central Obesity Indices Predict the Severity of Obstructive Sleep Apnea (OSA)?
}

\author{
BASMA GADELHAK, M.D.*; MONA EL-BESHBISHI, M.D.**; EMAN EL-NADY, M.Sc.*** and \\ MOHAMED EL-GAMAL, M.D.***
}

The Department of Diagnostic Radiology*, Faculty of Medicine, Mansoura University, Students' Hospital**, Mansoura University and Chest Medicine Department***, Faculty of Medicine, Mansoura University

\begin{abstract}
Background: Comparative evaluation of the CT measures of upper air way, tongue adiposity and central obesity in a group of obstructive sleep apnea (OSA) patients and in a control group, and their potential role in grading of OSA severity.
\end{abstract}

Aim of Study: The objective of the present study was to comparatively evaluate the different the upper air way, tongue adiposity and central obesity measures by CT scan in patients with obstructive sleep apnea syndrome (OSA) and in a control group, and their potential role in grading of OSA severity.

Material and Methods: This prospective case control study was carried out on 17 OSA patients diagnosed by PSG and 16 control subjects. Non contrast MDCT scan of the upper airway and mid abdomen was performed on Philips 128 detector scanner, $1 \mathrm{~mm}$ slice collimation during quite breathing. Axial and Sagittal reformatted images were assessed. Mandibular plane hyoid distance (MPH), upper airway length (UAL), minimum cross-sectional area (MCA), transverse and antero-posterior diameters of the airway (TDA, APD), length and thickness of uvula and soft palate (LUV,TUV), tongue area and tongue base density (TA, TD) were measured. Image $\mathrm{J}$ program was used for quantification of neck and visceral adipose tissue (NAT, VAT).

Results: Statistically significant difference was found in most CT measures between the OSA and control groups, the highest significant values were found with MCA, TDA, TUV and TA $(p<0.005)$. MCA and TA had the best diagnostic performance for OSA diagnosis. Statistically significant difference was found in MPH, UAL, MCA, TDA, TA, TD and NAT between the severe OSA and mild/moderate grades, The highest significant values was found with UAL and MCA $(p=0.001,0.002)$. For identifying severe OSA MCA, TDA and TA offered high diagnostic performances. Binary logistic regression found that TA and MPH were the significant predictors for severe OSA with overall $\%$ predicted $=88.2 \%$.

Conclusion: Our results indicate that CT offers added value in OSA diagnosis and prediction of severity, multiple

Correspondence to: Dr. Basma Gadelhak, E-Mail: basmagadelhak@hotmail.com.
CT measures varied significantly between OSA and control group as well as between different OSA grades.

Key Words: Computed tomography - Obstructive sleep apnea - Obesity.

\section{Introduction}

OBSTRUCTIVE sleep apnea (OSA) is a common sleep disorder, affecting approximately $2-4 \%$ of all middle-aged adults. OSA is characterized by recurrent episodes of upper airway (pharyngeal) collapse resulting in chronic intermittent hypoxia and interrupted sleep [1]. Obesity is the main risk factor for OSA, $80 \%$ of OSA patients are obese therefore OSA incidence is rising with the worldwide increase in obesity [2]

Continuous positive airway pressure (CPAP) is the standard treatment for OSA. Alternative treatments such as behavioral therapy, oral appliances, and surgery are recommended for OSA management if CPAP is not possible [1]

The definitive diagnosis of OSA requires an overnight Polysomnography (PSG); the total number of apneac (A) and hypopneac $(\mathrm{H})$ episodes divided by the number of hours of sleep produces an apnea-hypopnea index (AHI). This requires an overnight hospital stay and trained specialists to interpret the data [3,4]. Because of these limitations, various alternative diagnostic techniques have been proposed. The abnormal anatomy of the upper airway is the key diagnostic factor for OSA. A small upper airway cross sectional area and increased upper airway length are common anatomical variables however, no consensus has been reached regarding the most relevant measure [5-7]

Radiocephalometry is widely used however it is two dimensional in nature with hazy non-precise 
landmarks [8]. Computed tomography (CT) [9-15], cone beam CT (CBCT) [16], and magnetic resonance imaging (MRI) are 3D imaging techniques that allow better evaluation of the airway $[7,17,18]$ The major advantages of CBCT scanners are their lower radiation dose and cost in comparison with helical or multi-slice CT [16] MRI provides excellent resolution of soft tissue structures and their relationship with the upper airway without radiation exposure however, there is less precise bony definition $[\mathbf{7 , 1 8}]$. The diagnostic performances of these methods need further validation $[\mathbf{1 0 , 1 1 , 1 9 , 2 0 ]}$.

MDCT provides optimal delineation of the maxillofacial skeleton, upper airway dimensions and related soft tissue details [6,9-12,16,20,21].

Body mass index (BMI) is widely used as a measure of general obesity; the most important risk factor for OSA is elevated BMI [6] however it does not reflect the type of obesity. Central obesity can be determined by measuring neck circumference (NC) and waist circumference (WC) or more accurately by CT quantitative measures of the visceral adipose tissue (VAT) and neck adipose tissue (NAT) [22]

Awareness of the specific soft tissue and bony changes in OSA as well as patterns of airway narrowing can help radiologists to suggest the incidental diagnosis of OSA and to identify the possible etiology and level of airway obstruction in diagnosed cases [5]. For patients who have failed medical therapy and are considered for surgical procedures such as Maxillo-Mandibular Advancement; several studies recommended the use of imaging modalities for surgical planning, and outcomes assessment [9]

Regarding the role of CT in grading of OSA severity, there is still controversy regarding diagnostic efficiency of different CT measures [23]. We therefore investigated the differences in CT measures of upper airway, tongue adiposity and central obesity between OSA and non-OSA patients and among different OSA grades.

\section{Material and Methods}

The study was conducted from April 2019 to February 2020. Patients were referred from the Chest Department and underwent the CT scan in the Radiology Department, Mansoura University Hospital.

\section{Study design:}

This prospective case control study was carried out on 35 patients. 19 patients diagnosed with OSA clinically by sleep related symptoms and by Polysomnography and 16 subjects free from sleeprelated symptoms as a control group. 2 patients were excluded because of pregnancy in one patient and lost PSG results in another patient. Final study population were 33 subjects (17 in OSA group, 16 in Non-OSA group).

\section{Polysomnography:}

Standard overnight polysomnography (PSG) was performed for all patients in the OSA group and interpreted by experienced pulmonologist.

Apnea was defined as a reduction of $>90 \%$ of thermistor signal amplitude for at least $10 \mathrm{sec}$. Hypopnea was defined as a reduction of $>30 \%$ of nasal pressure amplitude for at least 10sec followed by oxygen desaturation $>3 \%$ or arousal. The apneahypopnea index (AHI) is the number of apnea and hypopnea events per hour of sleep. An AHI $>5$ is defined as OSA according to the American Academy of Sleep Medicine OSA severity is defined mild when AHI is between $>5-<15$, moderate with $\mathrm{AHI}>15-<30$ and severe if $\mathrm{AHI}>30$ [24].

\section{Non contrast CT of the upper airway and mid abdomen:}

Non contrast MDCT scan of upper airway and neck \& mid abdomen was performed on Philips 128 detector scanner, $1 \mathrm{~mm}$ slice collimation during quite breathing with patient in the supine position. Patients were instructed to remain still and not to swallow.

\section{Image analysis:}

Axial and Sagittal reformatted images of the airway were assessed. The following measures were included (Fig. 1):

- The level of obstruction retro-palatal (from the hard palate to tip of uvula), retro-glossal (from tip of uvula to hyoid bone opposite the tongue base) or multilevel obstruction [12].

- The mandibular plane to hyoid distance (MPH) was determined as the distance between the inferior margins of the mandible to the superior margin of hyoid on the sagittal plane [25]

- Upper airway length (UAL) from the hard palate to the base of the epiglottis (23),

- Minimum Cross sectional Area (MCA), AP and Transverse dimensions (TDA) of the retro palatal airway [6].

- Soft palate and uvula length (LUV) and maximum thickness (TUV).

- Tongue area (TA) was measured by tracing the tongue contour on the mid sagittal reformatted image [7]. 
- Tongue base density (TD) was measured to express fatty deposition of the tongue [25]

- Image J program was used for fat quantification after adjusting the fat threshold to -30 to -150
HU. Neck adipose tissue (NAT) will be assessed at the level of C5 vertebra (26) and Visceral adipose tissue (VAT) will be estimated at the level of L3 vertebrae [27] (Fig. 2).
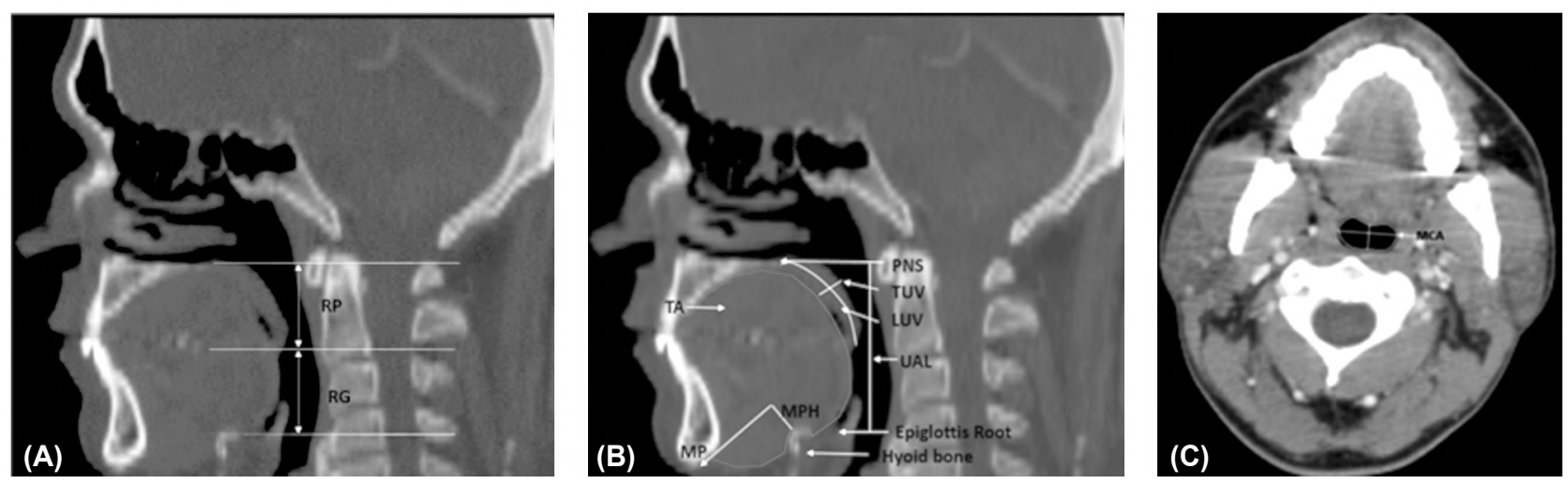

Fig. (1): CT images of a non OSA subject in the mid-sagittal (A,B) and axial planes (C). A. The retro-palatal (RP) and the retroglossal (RG) regions of the upper airway are demonstrated. B. CT measures of the Mandibular Plane Hyoid distance (MPH), Upper Airway Length (UAL), Length and Thickness of the Uvula (LUV, TUV) and Tongue Area (TA) are illustrated. C. Minimal cross sectional area (MCA), antero-posterior diameter (APD) diameter and transverse airway diameter (TDA) were measured at the retro-palatal region.
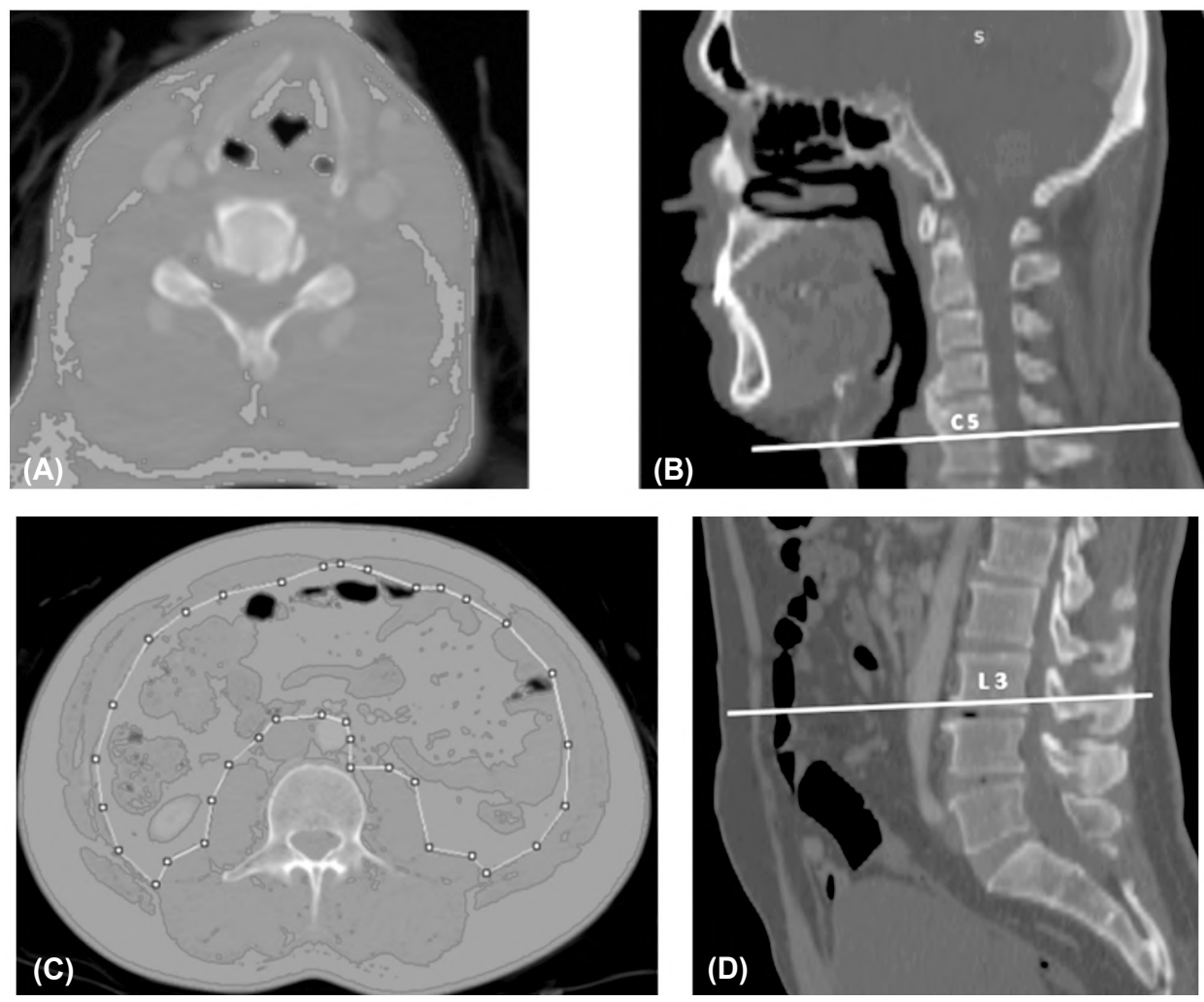

Fig. (2): CT fat quantification of the neck adipose tissue (NAT) at the level of C5 vertebrae (A,B) and visceral adipose tissue (VAT) at the level of L3 vertebra $(C, D)$ in a non-OSA subject.

\section{Statistical analysis:}

Data were fed to the computer and analyzed using IBM SPSS Corp. Released 2013. IBM SPSS Statistics for Windows, Version 22.0. Armonk, NY: IBM Corp. Qualitative data were described using number and percent. Quantitative data were de- scribed using median (minimum and maximum) for non-parametric data and mean, standard deviation for parametric data after testing normality using Kolmogrov-Smirnov test. Significance of the obtained results was judged at the (0.05) level. Data analysis was done using Mann-Whitney U 
test to compare 2 independent groups and Kruskal Wallis test was used to compare more than 2 independent groups with Mann Whitney $\mathrm{U}$ test to detect pair-wise comparison.

The diagnostic performance of a test, or the accuracy of a test to discriminate diseased cases from non-diseased cases is evaluated using Receiver Operating Characteristic (ROC) curve analysis. Sensitivity and Specificity were detected from the curve and PPV, NPV and accuracy were calculated through cross tabulation.

Binary stepwise logistic regression analysis was used for prediction of independent variables of binary outcome (cases). Significant predictors in the Univariate analysis were entered into regression model using forward Wald method. Adjusted odds ratios and their $95 \%$ confidence interval were calculated.

\section{Results}

The final study population included 16 control subjects; 7 males and 9 females. 17 OSA patients; 11 males $(65 \%)$ and 6 females $(35 \%)$. Age mean was $41 \pm 13 y$ and $39 \pm 9 y$ for OSA and non-OSA groups respectively. BMI was $29.4 \pm 4.9$ and $23 \pm 6.4$ $\mathrm{kg} / \mathrm{m}^{2}$ for OSA and non-OSA groups respectively. $\mathrm{NC}$ was $38.4 \pm 5.3 \mathrm{~cm}$ for OSA group, $31 \pm 3.1$ for non-OSA group. WC $96.2 \pm 13.9 \mathrm{~cm}$ for OSA versus $81 \pm 11$ in non OSA group.

Clinical symptoms in OSA group were Daytime sleepiness $(n=17)$, snoring $(n=12)$, Fatigue $(n=10)$ and poor concentration $(n=7)$. The mean AHI for OSA group was $30 \pm 27$, range 2 to 86 events $/ \mathrm{h}$. $23.5 \%$ of patients met the criteria of mild OSA with AHI $\leq 15(n=4), 41 \%$ of patients met the criteria of moderate OSA with AHI 15-30 $(n=7)$ and $35.5 \%$ of patients met the criteria of severe OSA AHI >30 $(n=6)$.

Comparing CT measures of OSA and non-OSA groups:

Variable CT measurements in an OSA patient are shown in Fig. (3). Table (1) summarizes the values of CT measures in the OSA and control non-OSA groups. ROC curve analysis for diagnostic performance of each significant $\mathrm{CT}$ parameter are shown in Fig. (4), Table (2).
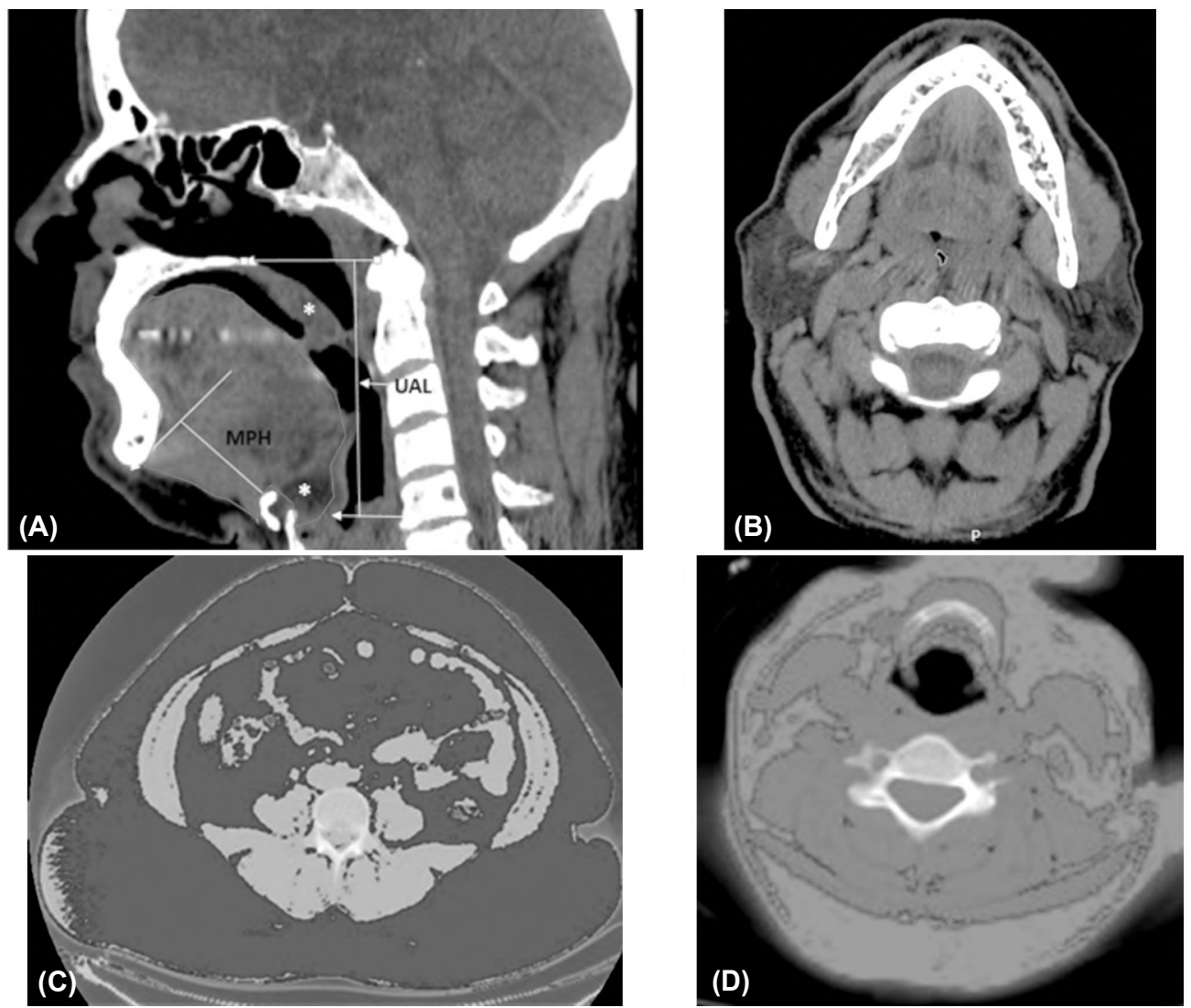

Fig. (3): CT images of a case of severe OSA A. mid sagittal image showing retro-palatal upper airway obstruction (RP). The air way is elongated with increase in the MPH and UAL, The tongue is enlarged with fatty deposition in the tongue base (white*). There is also increase thickness of the uvula (TUV) (yellow *). B. Axial image showing the marked reduction of the MCA. TDA and APD of the retro-palatal airway. C, D Marked increase of NAT and VAT quantified after adjusting the of CT images to fat threshold at -30 to -150 . 
Table (1): Comparison of CT measures of the upper air way, tongue adiposity and central obesity between obstructive sleep apnea (OSA) group and in the control group.

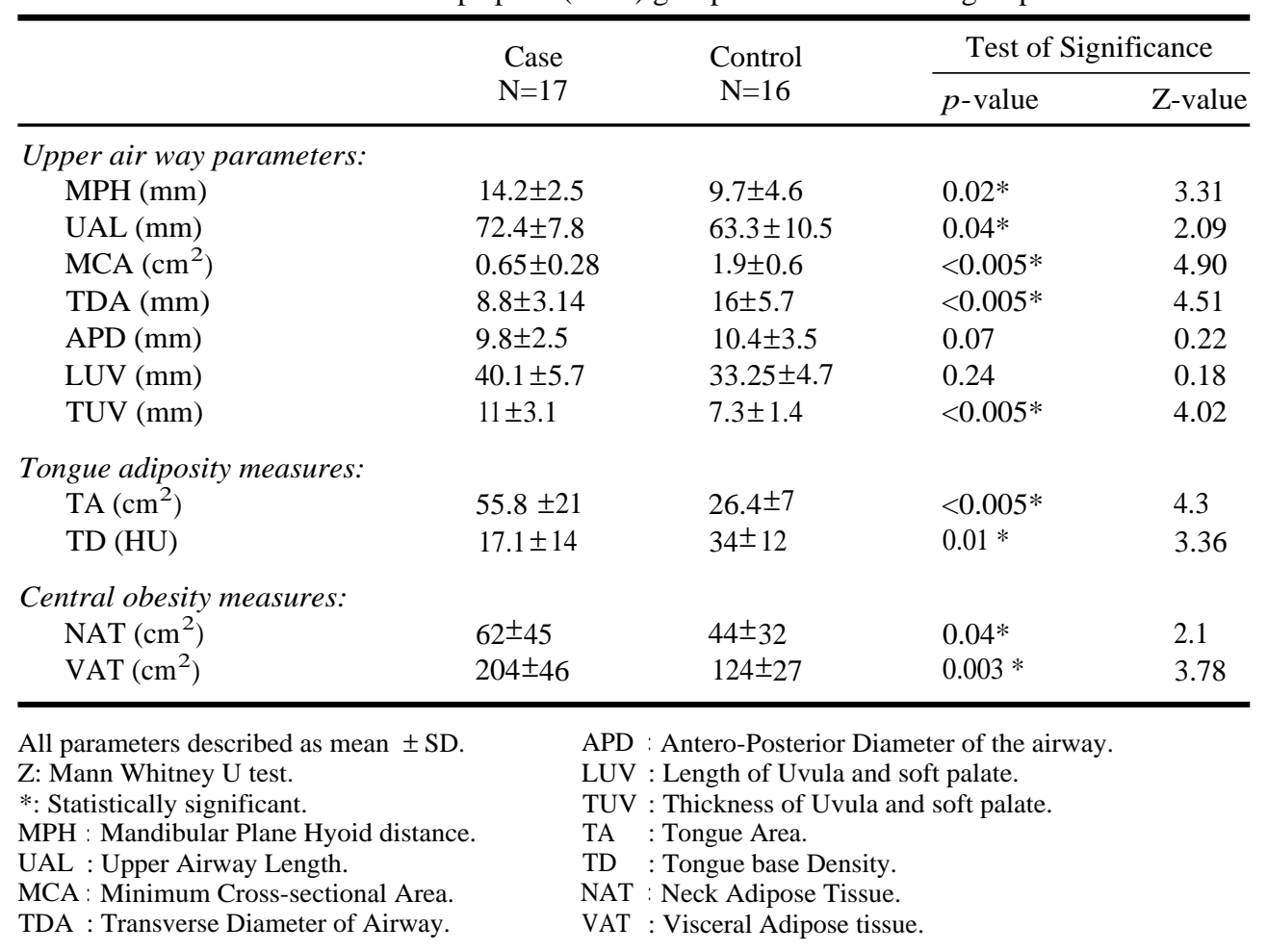
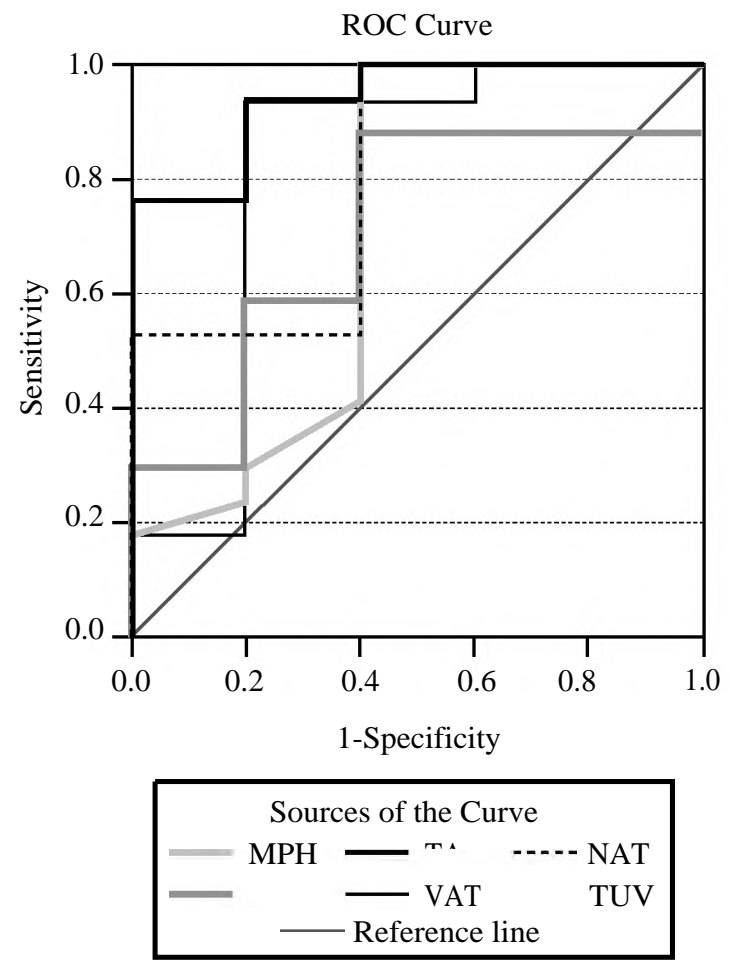

ROC Curve

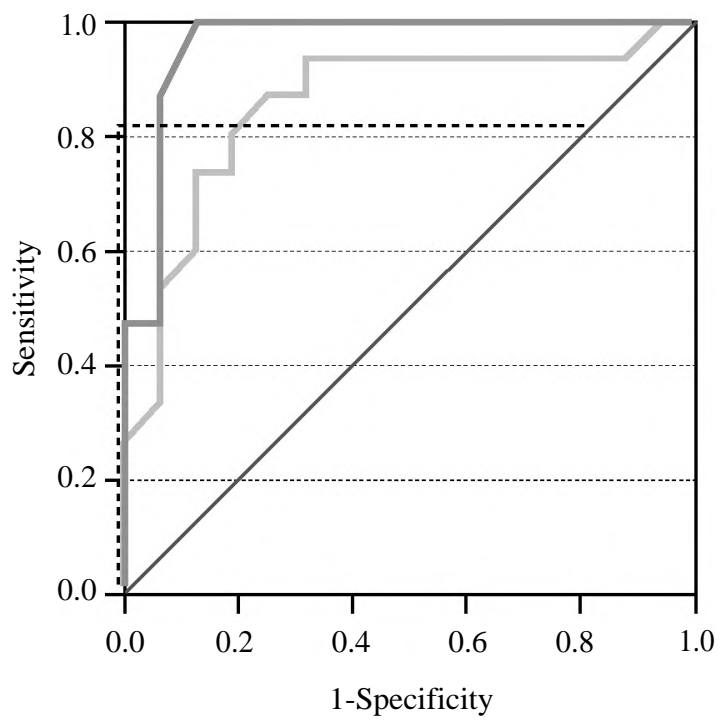

Sources of the Curve

$\begin{array}{ll}- \text { TD } & \text { TDA } \\ -\cdots \text { MCA } & \text { Reference line }\end{array}$

Fig. (4): ROC curve analysis for diagnostic performance of CT measures in OSA diagnosis Diagonal segments are produced by ties. 
Table (2): Validity of the studied measurements in the diagnosis of OSA.

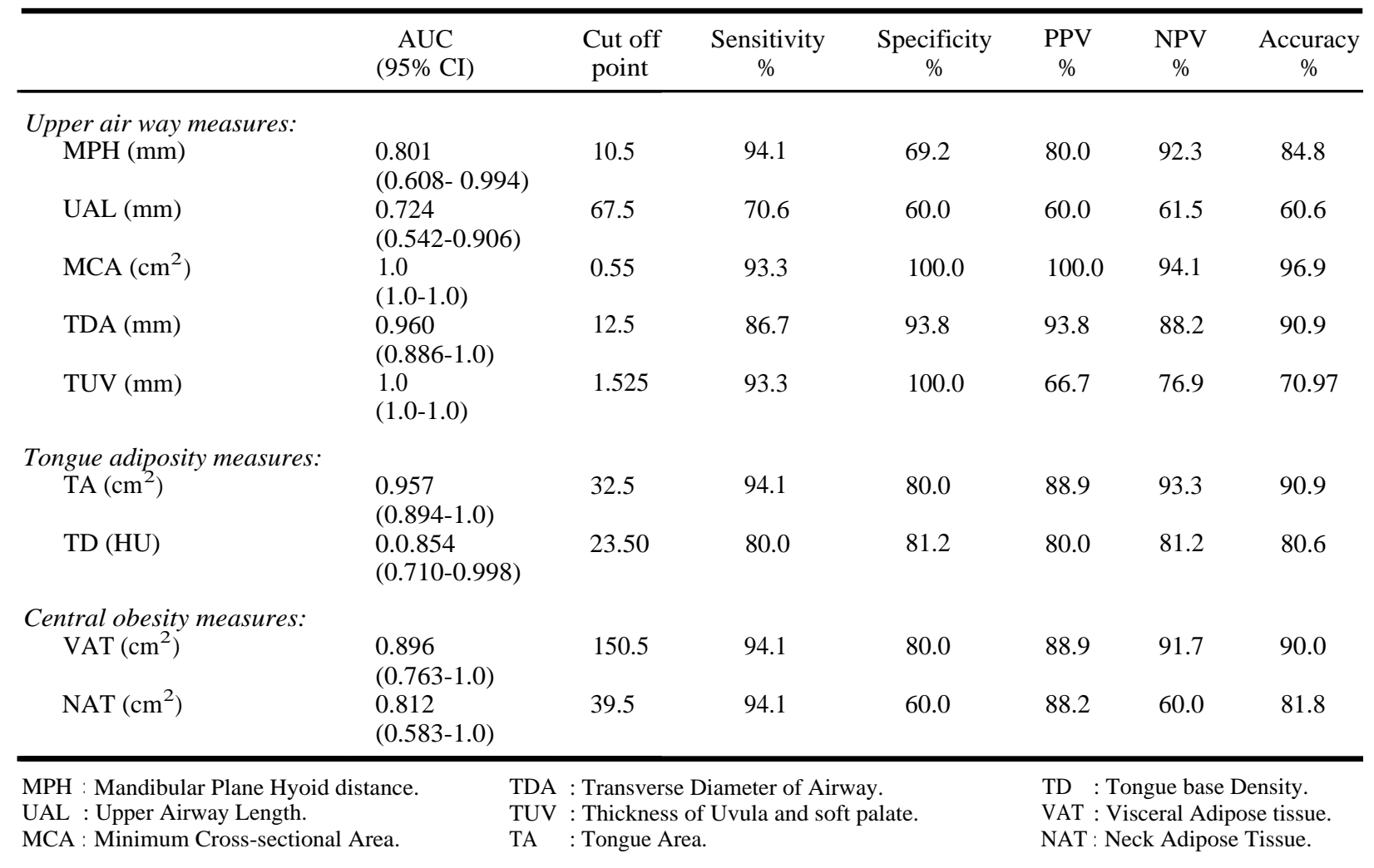

\section{Upper air way measures:}

Statistically significant differences were found in the MPH, UAL, MCA, TDA, TUV between the OSA group and the control group, $p$-values were $0.02,0.04,<0.005,<0.005,<0.005$.

Reduction of the MCA showed the highest diagnostic accuracy among airway measures. The best detected cutoff point was $0.55 \mathrm{~cm}^{2}$ yielding 93, 100, 100, 94 and 97\% sensitivity, specificity, PPV, NPP, accuracy respectively.

\section{Tongue adiposity measures:}

Both measures of tongue adiposity TA and TD were significantly different between the OSA group and the control group, $p$-values were $<0.005$ and 0.01 respectively.

On the ROC curve analysis the increase in tongue area (TA) above cutoff point $32.5 \mathrm{~cm}^{2}$ produces $94,80,89,93,91 \%$ sensitivity, specificity, PPV, NPP, accuracy respectively and the decrease in tongue density (TD) below cutoff point 23.5 HU produces $80,81,80,81$ and $80.5 \%$ sensitivity, specificity, PPV, NPP, accuracy respectively.

\section{Central obesity measures:}

Our case-control groups were not matched for BMI. Statistical significance was found in both NAT and VAT measures, however VAT showed higher significance $p=0.003$ compared to $p=0.04$ for NAT. The proposed cutoff point for VAT was $150 \mathrm{~cm}^{2}$ yielding sensitivity, specificity, PPV, NPP, accuracy of $94,84,89,92,90 \%$ respectively. While the cutoff point for NAT was $39.5 \mathrm{~cm}^{2}$ yielding sensitivity, specificity, PPV, NPP, accuracy of $88,60,88,60$ and $82 \%$ respectively.

\section{Comparing OSA grades and levels of airway obstruction:}

The level of upper airway obstruction was at the retro-palatal region in $70.5 \%$ of subjects $(n=12)$. Obstruction at the retro-glossal region was only found in one case $0.06 \%$. Multilevel obstruction was observed in $23.5 \%$ of cases $(n=4)$, all had severe OSA. Comparing the different CT measures and levels of airway obstruction among the different OSA grades are shown in Table (3).

\section{Upper air way measures:}

There was significant differences in UAL among different grades of OSA $(p<0.005)$. The MPH distance was significantly higher in severe OSA compared to the mild and moderate grades ( $p$ 0.039) while no significant differences was found between the mild and moderate OSA. There was significant reduction in the MCA and TDA in the severe OSA compared to mild/moderate grades and moderate OSA ( $p 0.042$ and 0.002$)$ respectively. 
No significant differences among OSA grades regarding the uvula length and thickness (LUV and TUV).

\section{Tongue adiposity measures:}

Tongue area (TA) as measured in the mid sagittal plane was larger is patients with severe OSA when compared mild/moderate grades $(p=0.01)$. Tongue base HU (TD) was significantly different between severe and mild OSA grades $(p=0.09)$, with no differences when comparing mild versus moderate OSA or Moderate versus severe groups.

\section{Body fat distribution measures:}

NAT differed significantly between the mild and severe OSA grades $(p=0.018)$. VAT values showed no significant difference among the OSA grades.

Table (3): CT measures of the upper air way, tongue adiposity and central obesity in Patients with Mild, Moderate and severe grades of Obstructive sleep apnea (OSA).

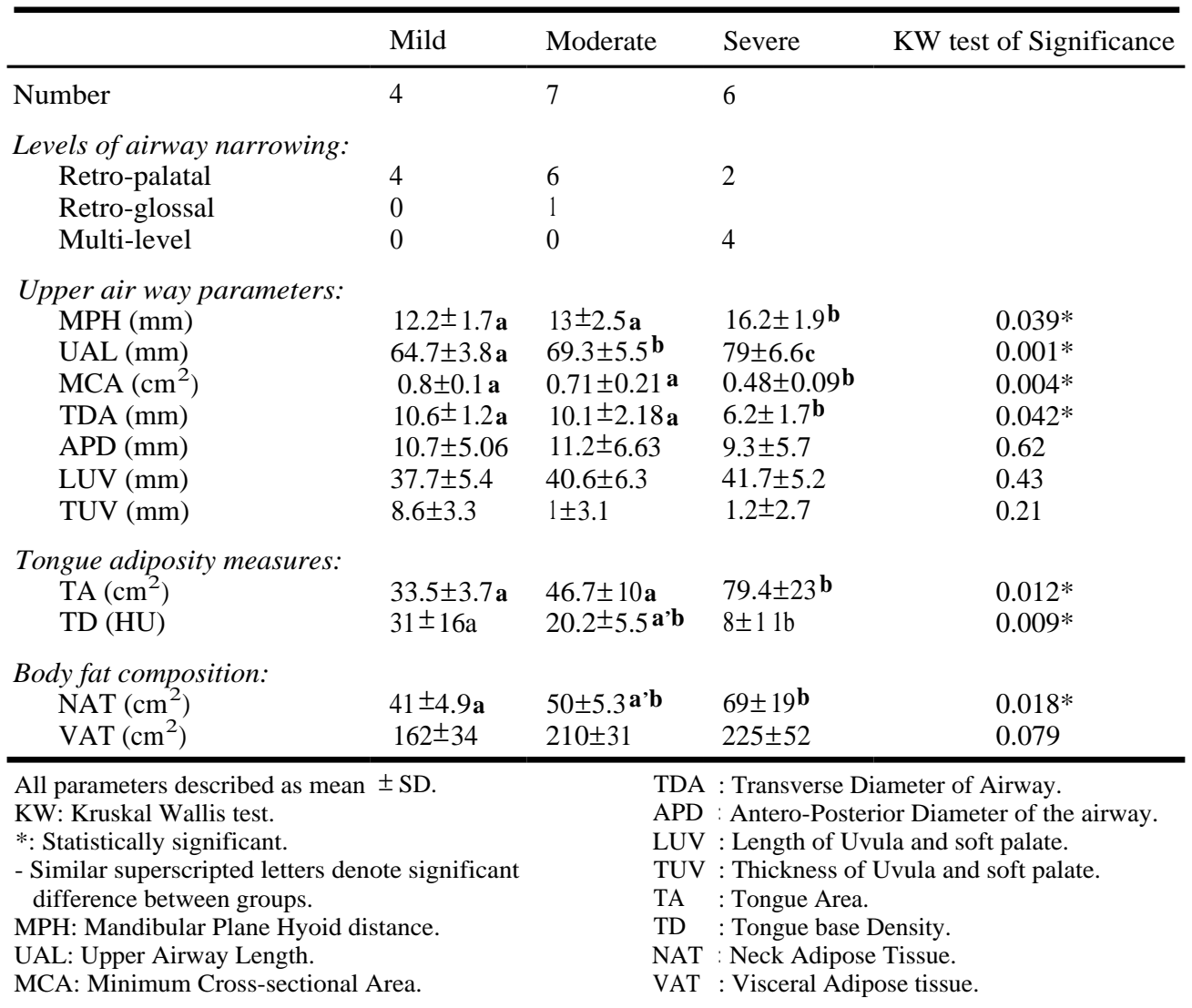

\section{Prediction of severe OSA:}

ROC curve analysis was done to detect cutoff points and diagnostic performance of the CT parameters in differentiating patients with severe grades of OSA from the mild/moderate grades Fig. (5), Table (4).

The reduction of MCA below cutoff point $0.31 \mathrm{~cm}^{2}$ showed the highest diagnostic performance with sensitivity, specificity, PPV, NPP, accuracy $100,91,86,100$ and $94 \%$ respectively. Followed by the increased TA above $58.5 \mathrm{~cm}^{2}$ and the reduced TDA below a cutoff point $6.9 \mathrm{~mm}$; both gave 83 ,
91, 83, 91 and $88 \%$ sensitivity, specificity, PPV, NPP, accuracy respectively. Increased NAT above a cutoff point of $56 \mathrm{~cm}^{2}$ yielded sensitivity, specificity, PPV, NPP, accuracy 83, 82, 71, 90 and $82 \%$ respectively for diagnosing severe OSA.

Binary logistic regression was done to detect predictors of severe OSA and found that TA and MPH were the significant predictors. With every increase one $\mathrm{mm}$ in TA increase risk of OSA by 1.14 (OR:1.14, 95\% CI : 1.02-1.28) with the overall $\%$ predicted was $88.2 \%$. Results of binary regression analysis of the severe OSA independent variables are shown in Table (5). 

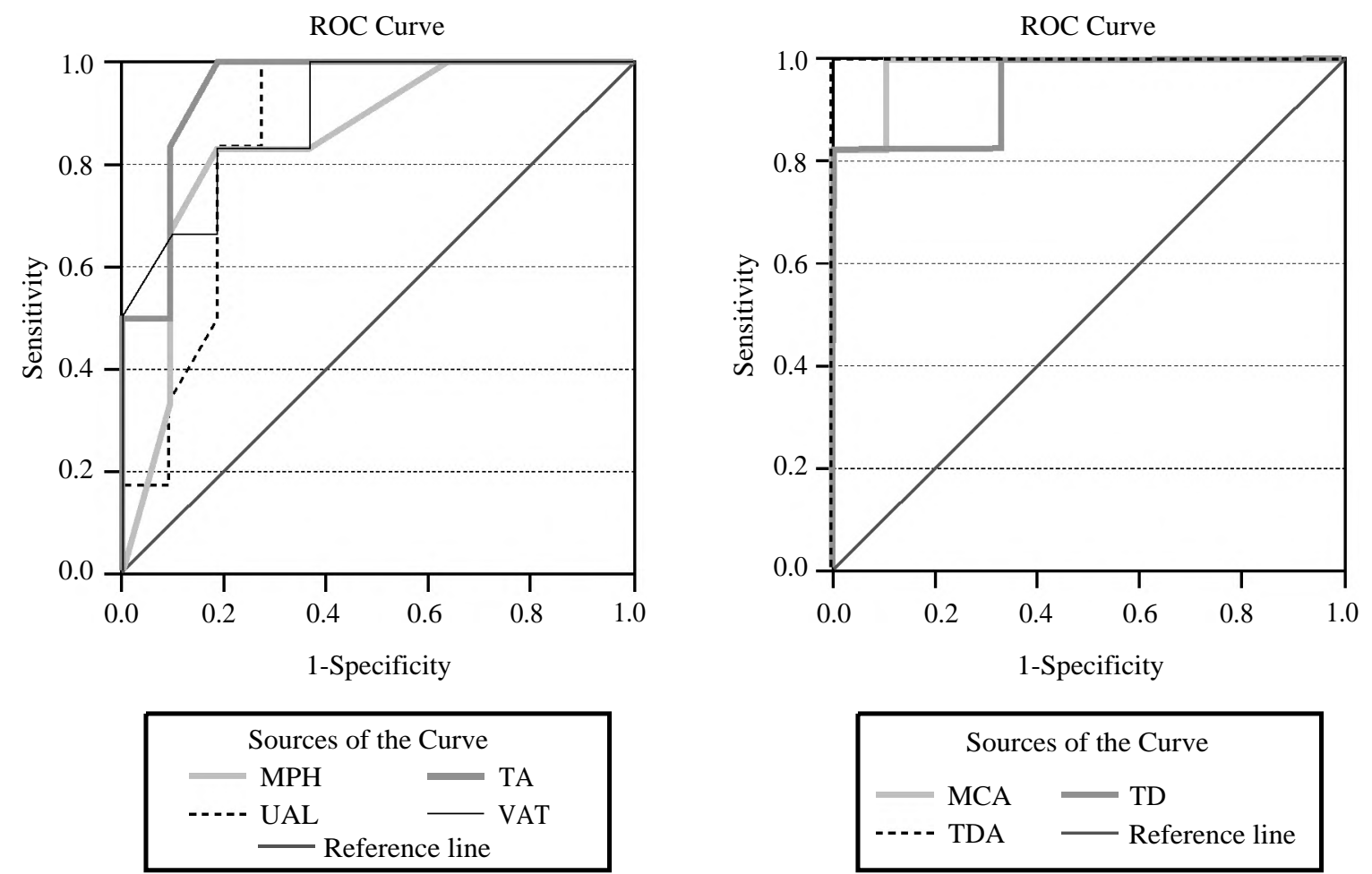

Fig. (5): ROC curve analysis for diagnostic performance of CT measures in severe OSA diagnosis Diagonal segments are produced by ties.

Table (4): Validity of the studied measurements in the diagnosis of severe OSA.

\begin{tabular}{|c|c|c|c|c|c|c|c|}
\hline & $\begin{array}{c}\text { AUC } \\
(95 \% \mathrm{CI})\end{array}$ & $\begin{array}{c}\text { Cut off } \\
\text { point }\end{array}$ & $\begin{array}{c}\text { Sensitivity } \\
\%\end{array}$ & $\begin{array}{c}\text { Specificity } \\
\%\end{array}$ & $\begin{array}{c}\text { PPV } \\
\%\end{array}$ & $\begin{array}{c}\text { NPV } \\
\%\end{array}$ & $\underset{\%}{\text { Accuracy }}$ \\
\hline \multicolumn{8}{|c|}{ Upper air way measures: } \\
\hline MPH (mm) & $\begin{array}{l}0.848 \\
(0.651-1.0)\end{array}$ & 14.5 & 83.3 & 81.8 & 71.4 & 90.0 & 82.4 \\
\hline $\mathrm{UAL}(\mathrm{mm})$ & $\begin{array}{l}0.856 \\
(0.673-1.0)\end{array}$ & 77.0 & 83.3 & 81.8 & 71.4 & 90.0 & 82.35 \\
\hline $\operatorname{MCA}\left(\mathrm{cm}^{2}\right)$ & $\begin{array}{l}1.0 \\
(1.0-1.0)\end{array}$ & 0.31 & 90.9 & 85.7 & 100.0 & 94.12 & 94.12 \\
\hline TDA (mm) & $\begin{array}{l}0.981 \\
(0.925-1.0)\end{array}$ & 6.94 & 83.3 & 90.9 & 83.3 & 90.9 & 88.2 \\
\hline \multicolumn{8}{|c|}{ Tongue adiposity measures: } \\
\hline TA $\left(\mathrm{cm}^{2}\right)$ & $\begin{array}{l}0.947 \\
(0.843-1.0)\end{array}$ & 58.5 & 83.3 & 90.9 & 83.3 & 90.9 & 88.2 \\
\hline $\mathrm{TD}(\mathrm{HU})$ & $\begin{array}{l}0.944 \\
(0.823-1.0)\end{array}$ & 15.0 & 83.3 & 88.9 & 83.3 & 88.9 & 76.5 \\
\hline $\begin{array}{l}\text { Central obesity } \\
\text { NAT }\left(\mathrm{cm}^{2}\right)\end{array}$ & $\begin{array}{l}0.947 \\
(0.753-1.0)\end{array}$ & 56.0 & 83.3 & 81.8 & 71.4 & 90.0 & 82.3 \\
\hline
\end{tabular}

All parameters described as mean \pm SD.

TDA : Transverse Diameter of Airway

MPH: Mandibular Plane Hyoid distance.

TA : Tongue Area.

UAL: Upper Airway Length.

MCA: Minimum Cross-sectional Area.

TD : Tongue base Density.

NAT : Neck Adipose Tissue. 
Table (5): Binary logistic regression in prediction of severe OSA.

\begin{tabular}{|c|c|c|c|}
\hline & P & $p$-value & OR (95\%CI) \\
\hline \multicolumn{4}{|l|}{$\begin{array}{l}\text { Upper air way } \\
\text { measures: }\end{array}$} \\
\hline MPH (mm) & 0.673 & $0.034 *$ & $1.96(1.05-3.65)$ \\
\hline UAL (mm) & 0.331 & 0.071 & $1.39(0.972-1.99)$ \\
\hline $\operatorname{MCA}\left(\mathrm{cm}^{2}\right)$ & -0.378 & 0.094 & $0.685(0.44-1.07)$ \\
\hline TDA (mm) & -74.67 & 0.99 & Undefined \\
\hline \multicolumn{4}{|l|}{ Tongue adiposity } \\
\hline $\mathrm{TA}\left(\mathrm{cm}^{2}\right)$ & 0.132 & $0.027 *$ & $1.14(1.02-1.28)$ \\
\hline TD (HU) & -47.19 & 0.17 & Undefined \\
\hline \multicolumn{4}{|l|}{$\begin{array}{l}\text { Central obesity } \\
\text { measures: }\end{array}$} \\
\hline $\operatorname{NAT}\left(\mathrm{cm}^{2}\right)$ & 0.019 & 0.186 & $1.02(0.99-1.05)$ \\
\hline \multicolumn{4}{|c|}{ Overall $\%$ predicted $=88.2 \%$} \\
\hline
\end{tabular}

MPH : Mandibular Plane Hyoid distance.

UAL : Upper Airway Length.

MCA : Minimum Cross-sectional Area.

TDA : Transverse Diameter of Airway.

TA : Tongue Area.

TD : Tongue base Density.

NAT : Neck Adipose Tissue.

\section{Discussion}

Combining different CT measures of the airway, tongue adiposity and central obesity helps in OSA diagnosis as well as prediction of severity. MCA below $0.55 \mathrm{~cm}^{2}$ and TA above $32.5 \mathrm{~cm}^{2}$ were the best parameters for OSA diagnosis. For identifying severe OSA reduced MCA below $0.31 \mathrm{~cm}^{2}$, reduced TDA below $6.9 \mathrm{~mm}$ and increased TA more than $58.5 \mathrm{~cm}^{2}$ offered high diagnostic performances. Binary logistic regression found that TA and MPH were the significant predictors for severe OSA.

In agreement with previous studies, the most common level of upper airway obstruction was the retro-palatal region, followed by the tongue base region. We found multilevel collapse in only $23.5 \%$ of cases, all had severe OSA. Chousangsuntorn et al., reported higher percentage of multilevel obstruction on their CT study likely because it was conducted during the apneic episode [11]

The MCA of the upper airway in the OSA group was significantly smaller than that of the non-OSA group. MCA is reduced by both the enlarged upper airway structures and the external pressure by the excess fat deposition in the neck. It was therefore considered as a key airway measure for OSA in our study as well as in several studies using different modalities $[6,7,12,17,28]$.
Lengthening of the upper airway as expressed by the significant increase of UAL and MPH distances was found in OSA patients compared to control. For grading of severity, UAL was significantly different among the three OSA grades, MPH was significantly different between severe OSA cases and both mild and moderate groups. Results from previous studies support ours $[\mathbf{7 , 2 0 , 2 1 , 2 5 ]}$.

We observed that OSA patients have larger tongue volumes with significantly increased TA and reduced TD compared to control group, significant differences were also found between the mild and severe OSA. The increased tongue adiposity in OSA patients was previously investigated $[\mathbf{1 4 , 2 0}]$ Barrera 2017 suggested that tongue volume is the strongest clinical predictor of OSA [6]

Obesity can cause OSA by different mechanisms. Expansion of parapharyngeal spaces with fat results in reduction of the transverse pharyngeal diameter and pharyngeal area. Deposition of excess fat in tongue base decreases its effciency as a pharyngeal dilator. Abdominal visceral adiposity decreases lung volumes, reduces traction on the pharynx and can lead to increased pharyngeal collapsibility and OSA $[17,25]$.

BMI does not reflect the extent of obesity [19] It is important to notice that subjects with similar BMI and WC can vary in their VAT and NAT measures [29].

The quantitative NAT and VAT measures in the current study were significantly higher in OSA group than in the control group. There was also significant difference between the NAT of the mild and severe OSA grades. Our results were in line with previous studies who reported correlations between the increases neck fat areas and the upper airway dimensions $[\mathbf{2 5 , 2 6 , 3 0 , 3 1 ]}$.

Regarding male and female distribution $65 \%$ of OSA patients in the current study were males. The difference in CT measures between males and females was not the subject of our study however previous studies have shown that UAL was significantly longer in men [32]. It was also observed that men have significantly more visceral fat than women in BMI matched groups which might explain the predisposition of men to OSA compared with women [29].

We chose the regular breathing, awake CT. Other investigators perform different techniques as imaging in the supine and lateral decubitus positions, Image acquisition with Muller maneuver, or during apneic episodes and in different phases of respiration $[\mathbf{1 0 - 1 2 , 2 0 ]}$ 
Although CT scanning during apneic episodes can provide more relevant anatomic and pathologic findings in high grades of OSA [11], scanning of awake patients without a sleep tracking system is more rapid, simple and applicable way. It can provide informative measures predictive of OSA [10]. CT during different phases of respiration was previously studied, one study found MCA at the end of inspiration was the most predictive measure for OSA severity [10]. Another study concluded that an awake upper airway CT scan can properly diagnose palate-pharyngeal obstruction; however, it was less sensitive for detecting retro-glossal obstruction [13]. High radiation dose is a main concern of the previous studies.

This work suffered from some limitations, the sample size was relatively small. Single investigator performed all the measurements so Interobserver agreement was not evaluated. The CT acquisition on awake subjects does not reflect the anatomy or physiology of the upper airway during sleep. The control patients had no symptoms or clinical evidence of breathing- or sleep-related symptoms but they did not have overnight PSG to confirm the absence of OSA. Finally OSA and control groups were not matched for age, sex and BMI.

\section{Conclusion:}

Our results indicate that $\mathrm{CT}$ offers added value in OSA diagnosis and prediction of severity, multiple CT measures varied significantly between OSA and control group as well as between different OSA grades. MCA and TA were the best parameters for OSA diagnosis. For identifying severe OSA MCA, TDA and TA offered high diagnostic performances. Binary logistic regression found that TA and MPH were the significant predictors for severe OSA.

\section{References}

1- PATIL S.P., AYAPPA I.A., CAPLES S.M., KIMOFF R.J., PATEL S.R. and HARROD C.G.: Treatment of adult obstructive sleep apnea with positive airway pressure: An American Academy of Sleep Medicine systematic review, meta-analysis, and GRADE assessment. J. Clin. sleep Med. JCSM Off Publ Am. Acad. Sleep Med., 15 (2): 301, 2019.

2- HUDGEL D.W., PATEL S.R., AHASIC A.M., BARTLETT S.J., BESSESEN D.H., COAKER M.A., et al.: The role of weight management in the treatment of adult obstructive sleep apnea. An official American Thoracic Society clinical practice guideline. Am. J. Respir. Crit. Care Med., 198 (6): e70-87, 2018.

3- ECKERT D.J., WHITE D.P., JORDAN A.S., MALHOTRA A. and WELLMAN A.: Defining phenotypic causes of obstructive sleep apnea. Identification of novel therapeutic targets. Am. J. Respir. Crit. Care Med., 188 (8): 996-1004, 2013.
4- HAILEY D., JACOBS P., MAYERS I. and MENSINKAI S.: The current status of autotitrating continuous positive airway pressure systems in the management of obstructive sleep apnea. Can. Respir. J., 12 (5): 271-6, 2005.

5- WHYTE A. and GIBSON D.: Imaging of adult obstructive sleep apnoea. Eur. J. Radiol., 102: 176-87, 2018.

6- CHEN H., AARAB G., de RUITER M.H.T., de LANGE J., LOBBEZOO F., van der STELT P.F.: Three-dimensional imaging of the upper airway anatomy in obstructive sleep apnea: A systematic review. Sleep Med., 21: 19-27, 2016.

7- BARRERA J.E., PAU C.Y., FOREST V-I., HOLBROOK A.B. and POPELKA G.R.: Anatomic measures of upper airway structures in obstructive sleep apnea. World J. Otorhinolaryngol. Neck Surg., 3 (2): 85-91, 2017.

8- KIM H.J., HONG S-N., LEE W.H., AHN J-C., CHA MS., RHEE C-S., et al.: Soft palate cephalometric changes with a mandibular advancement device may be associated with polysomnographic improvement in obstructive sleep apnea. Eur. Arch. Oto-Rhino-Laryngology, 275 (7): 18117, 2018.

9- ABRAMSON Z., SUSARLA S.M., LAWLER M., BOUCHARD C., TROULIS M. and KABAN L.B.: Threedimensional computed tomographic airway analysis of patients with obstructive sleep apnea treated by maxillomandibular advancement. J. Oral Maxillofac. Surg., 69 (3): 677-86, 2011.

10- CHOUSANGSUNTORN K., BHONGMAKAPAT T., APIRAKKITTIKUL N., SUNGKARAT W., SUPAKUL N. and LAOTHAMATAS J.: Upper airway areas, volumes, and linear measurements determined on computed tomography during different phases of respiration predict the presence of severe obstructive sleep apnea. J. Oral Maxillofac. Surg., 76 (7): 1524-31, 2018.

11- CHOUSANGSUNTORN K., BHONGMAKAPAT T., APIRAKKITTIKUL N., SUNGKARAT W., SUPAKUL $\mathrm{N}$. and LAOTHAMATAS J.: Computed tomography characterization and comparison with polysomnography for obstructive sleep apnea evaluation. J. Oral Maxillofac. Surg., 76 (4): 854-72, 2018.

12- KIM W.Y., HONG S-N., YANG S.K., NAM K.J., LIM K.H., HWANG S.J., et al.: The effect of body position on airway patency in obstructive sleep apnea: CT imaging analysis. Sleep Breath., 23 (3): 911-6, 2019.

13- TANG X.L., YI H.L., LUO H.P., XIONG Y.P., MENG L.L., GUAN J., et al.: The application of CT to localize the upper airway obstruction plane in patients with OSAHS. Otolaryngol. Neck Surg., 147 (6): 1148-53, 2012.

14- YING B., HUANG Q., SU Y., FU B., YE X., HUANG Y., et al.: 320-detector CT imaging of the upper airway structure of patients with obstructive sleep apnea-hypopnea syndrome. J. Craniofac. Surg., 23 (3): 675-7, 2012.

15- XIAO Y., CHEN X., SHI H., YANG Y., HE L., DONG J., et al.: Evaluation of airway obstruction at soft palate level in male patients with obstructive sleep apnea / hypopnea syndrome: Dynamic 3-dimensional CT imaging of upper airway. J. Huazhong Univ. Sci. Technol. [Medical Sci., 31 (3): 413, 2011.

16- DULTRA F.K.A.A., TAVARES A., de ALMEIDA DULTRA J., SALLES C., CRUSOÉ-REBELO I.M., BARBOSA I., et al.: Pharyngeal airspace of asthmatic individuals 
and those suffering from obstructive sleep apnea syndrome: Study by CBCT. Eur. J. Radiol., 95: 342-8, 2017.

17- TURNBULL C.D., WANG S.H., MANUEL A.R., KEENAN B.T., MCINTYRE A.G., SCHWAB R.J., et al.: Relationships between MRI fat distributions and sleep apnea and obesity hypoventilation syndrome in very obese patients. Sleep Breath, 22 (3): 673-81, 2018.

18- Razek A.A.KA.: Diagnostic role of magnetic resonance imaging in obstructive sleep apnea syndrome. J. Comput Assist Tomogr., 39 (4): 565-71, 2015.

19- KIM J. and LEE S.Y.: Obesity Indices Related to Obstructive Sleep Apnea in Obese Adults. J. Biosci Med., 5 (10): 34, 2017.

20- HUANG J-F., CHEN G-P., WANG B-Y., XIE H-S., ZHAO J-M., WU L-H., et al.: Assessment of upper-airway configuration in obstructive sleep apnea syndrome with computed tomography imaging during müller maneuver. Respir. Care., 61 (12): 1651-8, 2016.

21- KIM E.J., CHOI J.H., KIM Y.S., KIM T.H., LEE S.H., LEE H.M., et al.: Upper airway changes in severe obstructive sleep apnea: upper airway length and volumetric analyses using 3D MDCT. Acta. Otolaryngol., 131 (5): 527-32, 2011.

22- BLITMAN N.M., BARON L.S., BERKENBLIT R.G., SCHOENFELD A.H., MARKOWITZ M. and FREEMAN K.: Feasibility of using single-slice MDCT to evaluate visceral abdominal fat in an urban pediatric population. Am. J. Roentgenol., 197 (2): 482-7, 2011.

23- HIRATA R.P., SCHORR F., KAYAMORI F., MORIYA H.T., ROMANO S., INSALACO G., et al.: Upper airway collapsibility assessed by negative expiratory pressure while awake is associated with upper airway anatomy. $\mathrm{J}$. Clin. Sleep Med., 12 (10): 1339-46, 2016.

24- KAPUR V.K., AUCKLEY D.H., CHOWDHURI S., KUHLMANN D.C., MEHRA R., RAMAR K., et al.: Clinical practice guideline for diagnostic testing for adult obstructive sleep apnea: An American Academy of Sleep Medicine clinical practice guideline. J. Clin. Sleep Med., 13 (03): 479-504, 2017.
25- GODOY I.R.B., MARTINEZ-SALAZAR E.L., EAJAZI A., GENTA P.R., BREDELLA M.A. and TORRIANI M.: Fat accumulation in the tongue is ass ociated with male gender, abnormal upper airway patency and whole-body adiposity. Metabolism., 65 (11): 1657-63, 2016.

26- MARESKY H.S., SHARFMAN Z., ZIV-BARAN T., GOMORI J.M., COPEL L. and TAL S.: Anthropometric assessment of neck adipose tissue and airway volume using multidetector computed tomography: An imaging approach and association with overall mortality. Medicine (Baltimore), 94 (45), 2015.

27- GOMEZ-PEREZ S.L., HAUS J.M., SHEEAN P., PATEL B., MAR W., CHAUDHRY V., et al.: Measuring abdominal circumference and skeletal muscle from a single cross-sectional computed tomography image: A step-bystep guide for clinicians using National Institutes of Health Image J. J. Parenter Enter Nutr., 40 (3): 308-18, 2016.

28- OGAWA T., ENCISO R., SHINTAKU W.H. and CLARK G.T.: Evaluation of cross-section airway configuration of obstructive sleep apnea. Oral Surgery, Oral Med. Oral Pathol. Oral Radiol. Endodontology, 103 (1): 102-8, 2007.

29- HARADA Y., OGA T., CHIHARA Y., AZUMA M., MURASE K., TOYAMA Y., et al.: Differences in associations between visceral fat accumulation and obstructive sleep apnea by sex. Ann. Am. Thorac. Soc., 11 (3): 383 91, 2014.

30- GLICKSMAN A., HADJIYANNAKIS S., BARROWMAN N., WALKER S., HOEY L. and KATZ S.L.: Body fat distribution ratios and obstructive sleep apnea severity in youth with obesity. J. Clin. Sleep Med., 13 (04): 545$50,2017$.

31- FRANCO I., REIS R., FERREIRA D., XARÁ S., FERREIRA W., BETTENCOURT N., et al.: The impact of neck and abdominal fat accumulation on the pathogenesis of obstructive sleep apnea. Rev. Port Pneumol., 22 (4): 240-2, 2016.

32- MALHOTRA A., HUANG Y., FOGEL R.B., PILLAR G., EDWARDS J.K., KIKINIS R., et al.: The male predisposition to pharyngeal collapse: Importance of airway length. Am. J. Respir. Crit Care Med., 166 (10): 1388-95, 2002. 


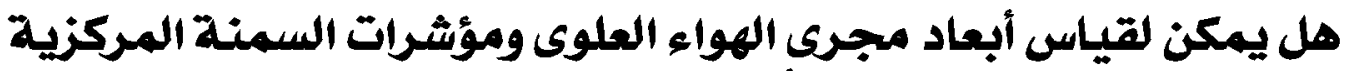

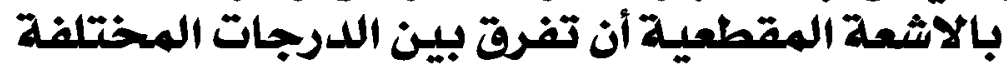

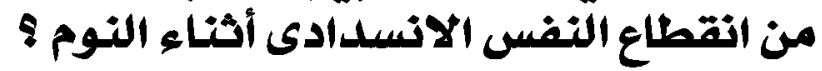

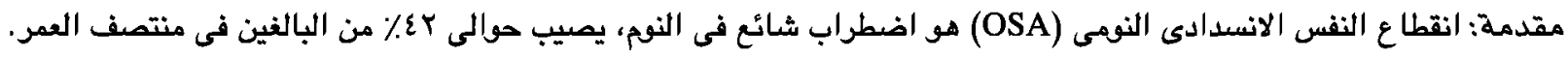

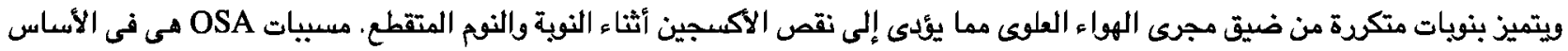

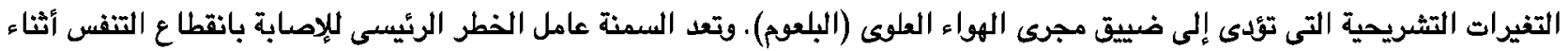

يعتمد تشخيص انقطاع التنفس أثناء النوم على مقياس خاص اللنوم وهو ما يحتاج بقاء المريض في المستشفى طوال الليل كما يتطلب

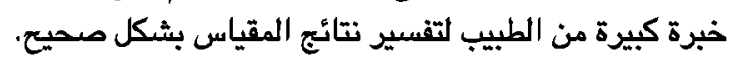

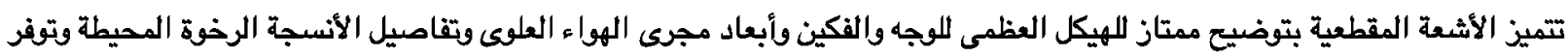
الأشعة المقطعية أيضاً معلومات مباشرة حول توزيع الد هون في الجسم. لذالك يمكن أن تكون احد بدائل تشخيص انقطاع العاد النفس أثناء النوم بدرجاته المختلة.

الهدف من الدراسة: تقييم أبعاد مجرى الهواء العلوى ومقاييس السمنة المركزية في مرضى انقطاع النفس الانسدادى أثناء النوم مقارنة

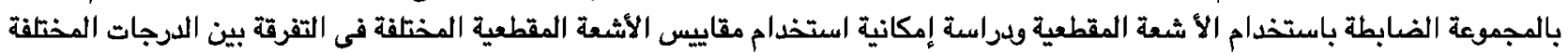
لانقطاع النفس الانسدادى أثثاء النوم.

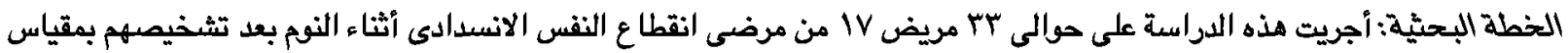

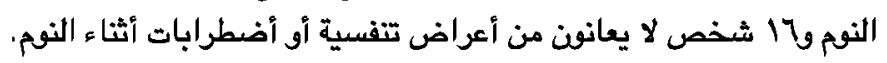

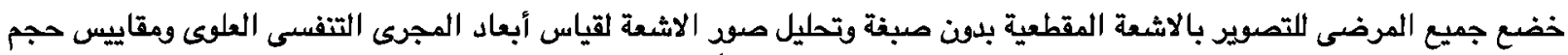

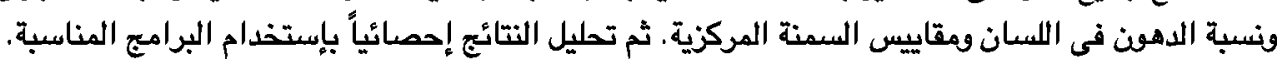

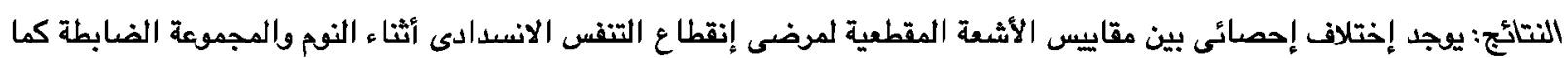

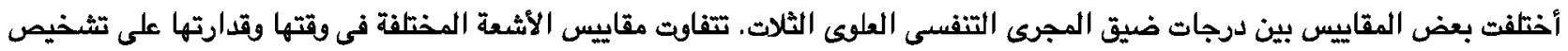

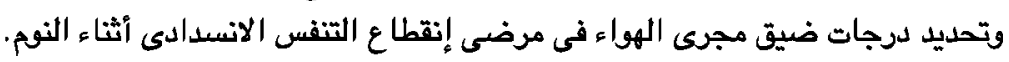

